\title{
Radiographic Image Not Correlated with Tumor Pathology Finding
}

National Cancer Institute

\section{Source}

National Cancer Institute. Radiographic Image Not Correlated with Tumor Pathology

Finding. NCl Thesaurus. Code C137940.

An indication that the results from radiographic and pathological testing do not correlate. 